tury, railroad workers frequently were maimed when coupling rail cars. But automatic couplers, invented in 1873, were not installed by rail companies until an 1893 law required them. As it turned out, this 20 year frame was about right for air bags, too.

The federal safety standards that Haddon set have been credited with preventing thousands of crash deaths and hundreds of thousands of serious crash injuries each year in the United States. But that is only part of it - those initial vehicle safety standards were adopted, sometimes almost as written by Haddon and his associate Bob Brenner, in many other developed countries. For Bill, this was especially gratifying because he was always trying to spread his ideas far and wide. He visited Australia on more than one occasion to expound his views. Peter Vulcan can tell you how influential one of those early visits was.

Because of Haddon's vision and accomplishments, tens of thousands of people are either alive or uninjured. Automobiles are safer to operate and more protective. They are less subject to damage and easier and less expensive to repair. Air bags are saving hundreds of lives each year and preventing thousands of injuries. And the broad field of injury control is growing in acceptance as a discipline for scientific study.

Because of Haddon's pioneering work, we now have data to guide this field. We have good scientific papers - this morning we are going to hear five examples. A former chairman of the institute once predicted that if we can continue his work, Bill Haddon will have saved more lives than anyone since Louis Pasteur. The papers presented in this session were chosen as exemplars of the work that will help bring about this prediction.

BRIAN O'NEILL President

Insurance Institute for Highway Safety, 1005 N Glebe Road,

Arlington,

$V A$ 22201, USA

(This paper was given at Third International Conference on Injury Prevention and Control, Melbourne, 22 February 1996.)
If we were able to define health, perhaps we would have an easier time coming to grips with the challenge of developing health status measures. Health, Sir Geoffrey Vickers once said in another context, is a successive redefinition of the impossible. If this is the case (as it must be), then conceptualizations of health will change over time. The development of health status measurement over the past 150 years is testimony to this truism. Health status was initially measured by mortality rates, and the interntional Classification of Diseases (ICD) brought international standards to the effort to develop comparable ways to code cause of death. Much later, the focus on prevention and treatment of diseases led to efforts to collect information on causes of morbidity, first using the ICD and then a more 'practice friendly' coding system known as the ICHPPC (International Classification of Health Problems in Primary Care). Growing recognition of the importance of physical dysfunction to health and well being in populations was associated with the development, by the World Health Organization, of a system to classify impairments, disabilities, and handicaps. Growing recognition of the importance of primary care within a health system, and of the importance of people's perceptions of their health problems, has recently led to a classification of health problems, known as the ICPC (International Classification of Primary Care); this organizes, in a standard way, the description of health experiences that are not resolvable to a diagnosis or that reflect people's experiences with their illnesses in physical or mental terms, albeit still within a biomedical framework.

We have, however, entered a new era. We are coming to recognize that biomedically defined illness, whether characterized by diagnoses or by problems, is no longer sufficient to represent the impact of illness on people in specific or on society in general. Thus, the field of health status measurement has added consideration of functional status and quality of life. Functional status is the representation of medical morbidity in the daily life of people how it affects their perceptions of themselves and how it influences their behavior in daily activities. Quality of life is conceptually broader, taking into account how people feel about their lives and what they are able to do. In practice, however, most quality of life measures are forms of functional status measures but represented by an overall score rather than by a profile of different domains; these scores can then be aggregated to characterize populations rather than individual patients.

Functional status measures, which include a variety of domains, have great utility in assessment of population and patient needs and in evaluations of the efficacy and effectiveness of interventions to improve health or prevent its deterioration. We now know, and Dr Kopjar's paper in this issue of the journal has provided further evidence, that manifestations of illness or injury are found in a variety of aspects of health, not even limited to the physical, mental, or role functioning domains. That is, to measure health is to measure not only conventional biopsychosocial representations of physical or mental disorder but also to assess people's own characterization of their physical and mental health and their functioning.

Health status measurement is now moving increasingly towards the use of multidomain approaches such as the SF-36, which was developed for adults. These are 'generic'; that is, they are not specific to any type of illness but, rather, intended for use is assessing the general health of populations and detecting systematic differences across specific population subgroups or for documenting the general impact of health services interventions. Because they are 'generic', they are unlikely to be sensitive enough to capture those aspects of illnesses or injuries that are 
potentially amenable to specific types of interventions. For this purpose, the generic measure should be complemented by a disease specific or injury specific module as needed.

Would an SF-36 like instrument be enough to measure health in childhood, at least for now? I think not. In the case of young people, it is not enough to know their rates and causes of mortality, to know about their illnesses (whether acute or chronic), or to know their levels of disability and the states of their functioning. Young people are thought to be largely healthy and, by these adult standards of health, they are certainly more healthy than their elders. But there is another aspect of health that is more pertinent for children than for adults, and that is their resilience and vulnerability. A child or youth is not optimally healthy if he or she evinces characteristics that indicate a high likelihood of subsequent deterioration in health. Conversely, a resilient child - one who has resources that make him or her more resistant to the threats of deterioration - is healthier.

My colleagues and I have developed a 'long form' instrument for assessing health status of youth of ages $11-17$ years. This instrument has been validated in several different populations; its properties have been published in the literature. ${ }^{1}$ Our research group is actively working on several extensions of this work: a short version, a computerized version, and a version for children of aged 5-10.
In contrast to existing instruments, the $\mathrm{CHIP}-\mathrm{AE}^{\circledR}$ contains domains for resilience and vulnerability, as well as for disorders, discomforts, satisfaction with health, and achievement of social expectations. We are also nearing completion of work to develop specific profiles of health since there appear to be a limited number of patterns of scores across the six domains that can capture the full range of types of 'health' in adolescent populations. These profile descriptions should make our attempts at intervention much more informed and, thereby, more effective.

Thus, we have come a long way in the conceptualization of health and in its measurement. But our work will never be done. That which was once unfathomable becomes potential and then possible. Such is the challenge of our work.

BARBARA STARFIELD

University Distinguished Service Professor

Department of Health Policy and Management,

The fohns Hopkins University School of Hygiene and Public Health, 624 North Broadway, Room 452,

Baltimore,

MD 21205-1996, USA

1 Starfield B, Riley AW, Green BF, et al. The adolescent CHIP: a populationbased measure of health. Med Care 1995; 33: 553-6.

\section{Reflecting reindeer}

Jan Shield kindly sent the following clipping from The Age: 'About 70000 Swedish reindeer have been fitted with reflectors to protect them from traffic accidents, with the resultant number of collisions down 27 per cent'. My reaction, If its good for reindeer, why not for children? Is there a mysterious message here?

\section{Our values?}

The revolver used by bandit Jesse James has been sold for $\$ 230000$ and a rifle presented to Teddy Roosevelt in 1909 was auctioned for $\$ 600000$, according to an editorial in the Medical Post (5 December 1995). A London gun expert says a good gun is a better investment than a good car, increasing in value by $20 \%$ in a few years. Still, gun owners object to the cost of a permit that would license their weapon. Funny old world!

\section{More on guns}

A study published in the December 1995 issue of Archives of Pediatric and Adolescent Medicine found that $25 \%$ of 3-4 year olds and $70 \%$ of 5-6 year olds had enough finger strength to fire nearly all of 64 handguns commonly sold in the US. A second study (in the same issue) reported that children who carry knives to elementary school to defend themselves or attack others are more likely to carry guns as high school students several years later (Washington Post, S Goodman).

\section{Request for injury prevention in sports}

Dr Caroline Finch has issued a request for literature on injury prevention strategies applicable to equestrian sports, skiing, snowboarding, cricket, softball, baseball, and soccer. She is particularly interested in formal evaluations of countermeasures. Contact: Caroline Finch, Monash University Accident Research Centre, Bldg 70, Wellington Road, Clayton, Victoria 3168, Australia. 